\title{
Simulation of damage process of containership's side structure due to collision with a rock
}

\author{
Grzegorz Porembski \\ DesArt, Gdynia \\ Janusz Kozak \\ Gdansk University of Technology
}

\begin{abstract}
This paper presents methods and results of a simplified numerical simulation of collision process of containership's side structure and a rock. Analysis of results of the modeling makes it possible to draw conclusions as to a character of the event as well as to estimate area and depth of damage caused by the penetrating rock, in order to select geometry of a filler and impermeable layer of $2^{\text {nd }}$ protection barrier.
\end{abstract}

Keywords: collision, LSDYNA, FEM, numerical simulation.

\section{INTRODUCTION}

Models for analyzing ship collisions appeared in the 1950s to investgate consequences of collisions of ships for transport of radioactive materials. The models were later adjusted to other types of ships - barges, tankers or LPG/LNG carriers. A systematic review of approaches to collision modeling was published in 1997 [1], showing that several models based on different assumptions were in use. Generally, collision of ships is an event of large energy changes within a short time, usually described mathematically by the equations of energy conservation and moment equilibrium, and during which hulls of two ships come in mutual contact in such way that structural failure of at least one of them occurs.

\section{MODELING THE COLLISION PROCESS}

Collision between two ships is usually modeled as a nonelastic interaction. The interaction is defined as that in which a part of kinetic energy of colliding objects is transformed into other form of energy (e.g. work of damaging, heat etc) For the conditions of non-elastic collision the following equations of equilibrium of moments and energy can be defined $[2,3,4]$ :

$$
\begin{gathered}
\mathrm{M}_{1} \mathrm{~V}_{1}+\mathrm{M}_{2} \mathrm{~V}_{2}=\left(\mathrm{M}_{1}+\mathrm{M}_{2}\right) \mathrm{V}_{3} \\
\frac{1}{2}\left(\mathrm{M}_{1} \mathrm{~V}_{1}^{2}+\mathrm{M}_{2} \mathrm{~V}_{2}^{2}\right)=\frac{1}{2}\left(\mathrm{M}_{1}+\mathrm{M}_{2}\right) \mathrm{V}_{3}^{2}+\mathrm{E}_{\mathrm{A}}+\mathrm{E}_{\mathrm{F}}
\end{gathered}
$$

where:

$M_{1}$ - mass tensor of hiting ship (together with added masses)
$\mathrm{M}_{2}$ - mass tensor of hit ship (together with added masses)

$\mathrm{V}_{1}-$ hiting ship velocity vector

$\mathrm{V}_{2}-$ hit ship velocity vector

$\mathrm{V}_{3}$ - velocity vector of both the ships after hit

$\mathrm{E}_{\mathrm{A}}$ - amount of energy absorbed to deform and/or damage the structure

$\mathrm{E}_{\mathrm{F}}$ - amount of energy transferred to surrounding water during collision.

As shown below, the perpendicular hit of bow of one ship against midship part of the other is an often occurring case of collision, Fig. 1 and 2.

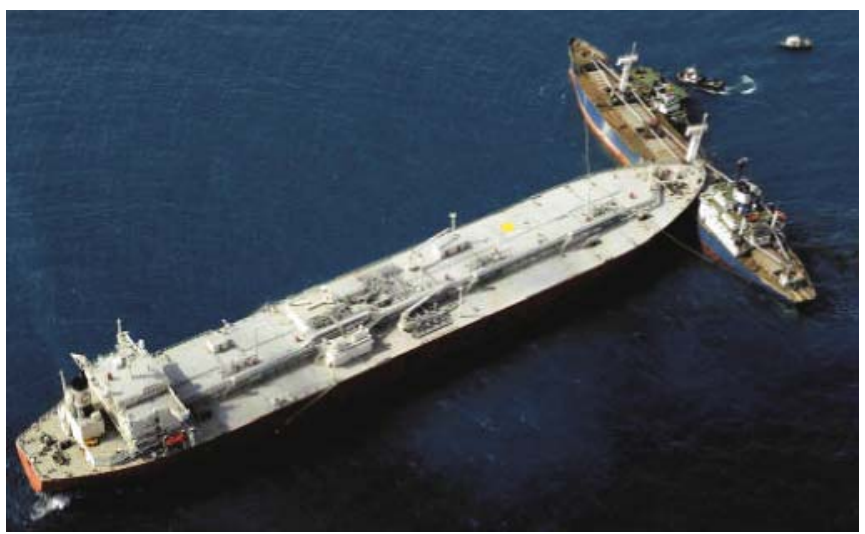

Fig. 1. Collision of $m / t$ Gas Roman and $m / v$ Springbok [2]

During such hit - if the hiting ship is fitted with a bow bulb - a damage of hit ship's plating and supporting structure in its bilge zone below waterline, is possible. In this zone fuel 
oil tanks are usually installed. Hence such type of collision produces a risk of loss of tightness of a tank and leakage of fuel oil contained in it to surrounding water, that can result in environmental pollution. This paper presents a fragment of the work performed in the frame of the CORET project realized within the Eureka E! 3614 project. In the frame of the project, 3-D geometrical model of cargo part of a containership was elaborated. On this basis FEM model which initially served to perform several test analyses to verify modeling process regarding continuity and static effort, was built. After the verification the prepared model was used to make the below presented collision analysis.

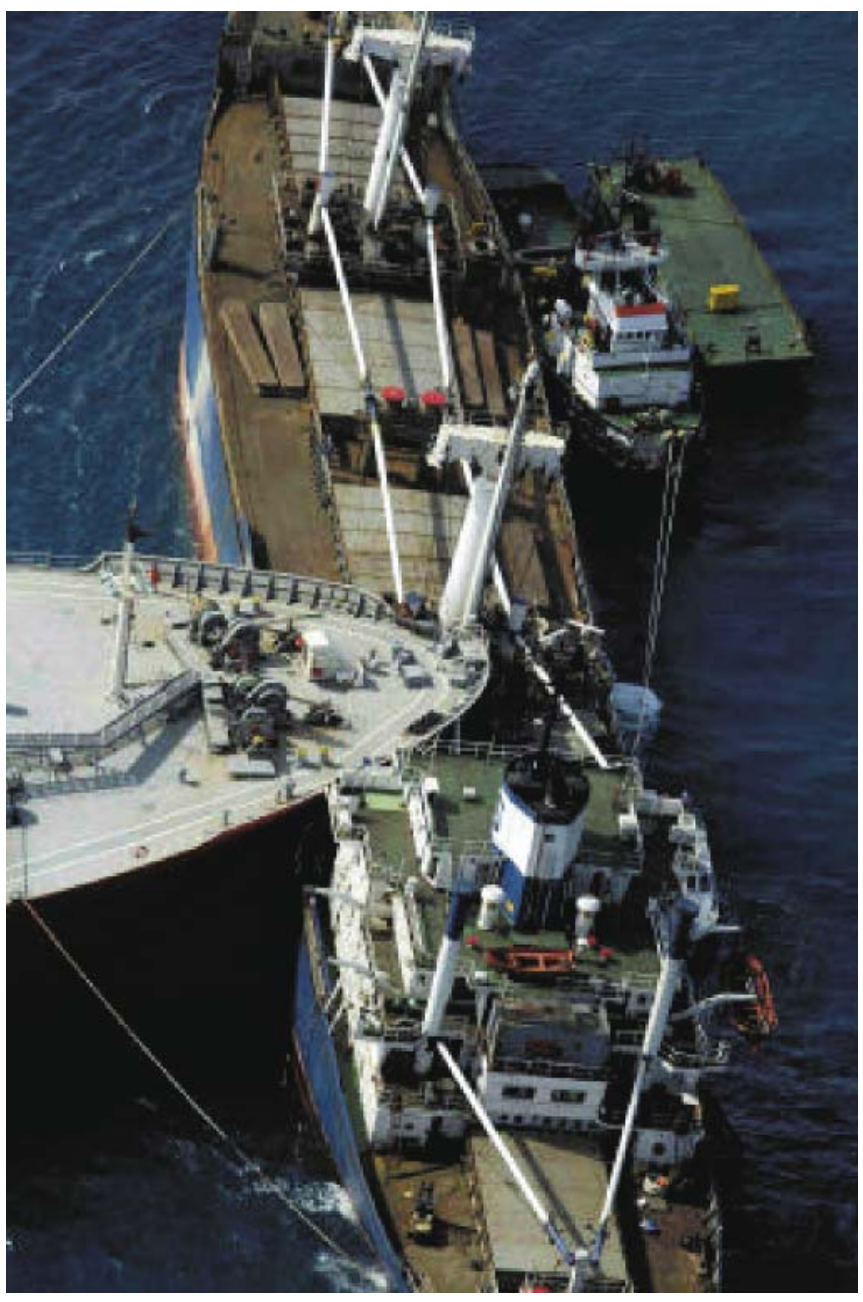

Fig. 2. A detail of side structure penetration during collision of $\mathrm{m} / \mathrm{t}$ Gas Roman and $\mathrm{m} / \mathrm{v}$ Springbok [2].

\section{NUMERICAL MODEL}

The simulation was performed for the hull of 950 TEU containership of the following main particulars:

$\begin{array}{ll}\text { Overall length } & 138.10 \mathrm{~m} \\ \text { B.p. length } & 132.00 \mathrm{~m} \\ \text { Breadth } & 22.50 \mathrm{~m} \\ \text { Depth to main deck } & 11.20 \mathrm{~m} \\ \text { Design draught } & 7.60 \mathrm{~m} \\ \text { Calculation draught } & 8.55 \mathrm{~m}\end{array}$

The entire cargo part of the ship was modeled. It was assumed that the hit against the rock occurs in the zone between the frame no. 86 and 121, therefore the FEM grid in the zone was made more dense, and in the remaining part of the model it was left relatively rough. In all the model, webs of the frames were modeled with finite shell elements, webs of the plating stiffeners in the zone between frame no. 86 and 121 - with finite shell elements, and in the remaining zones - with finite beam elements. And, flanges of the stiffeners and frames were modeled with finite beam elements within all the model, Fig. 3.

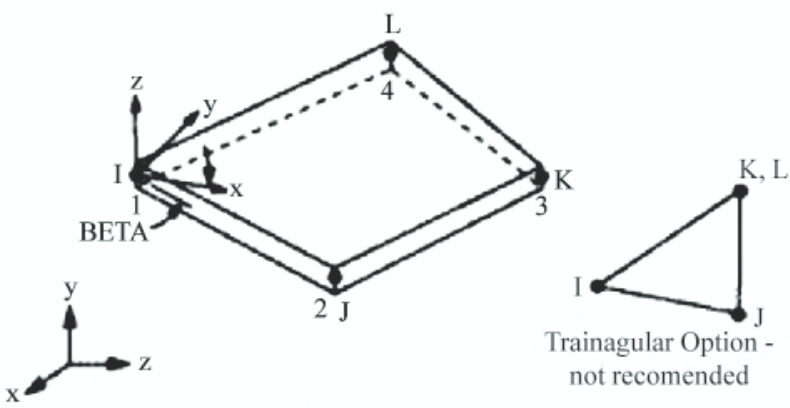

Note: $\mathrm{x}$ and $\mathrm{y}$ are in the plane of the element
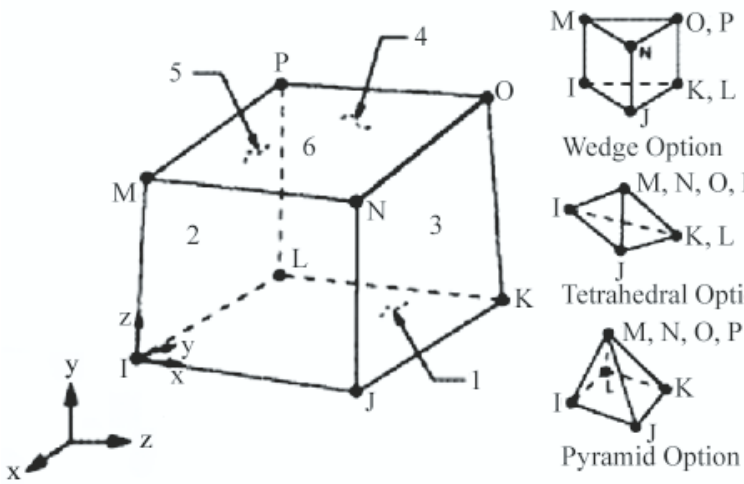

Wedge Option

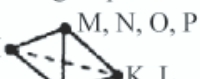

Tetrahedral Option

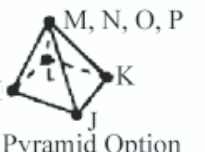

Fig. 3. Forms of finite shell and solid elements appplied to the analysis

To form the numerical model, 82574 shell elements and 1000 solid elements were used altogether, Fig.4.

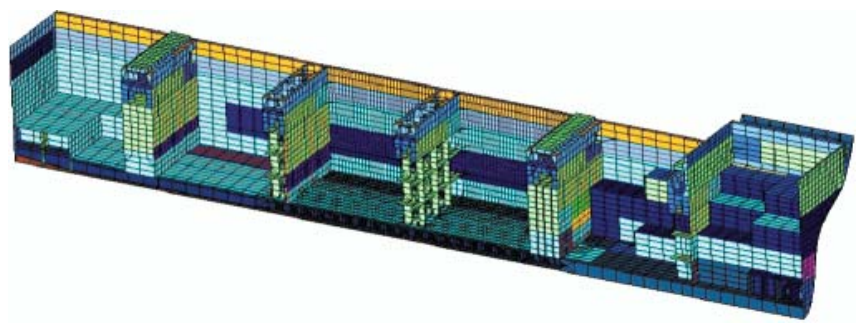

Fig. 4. FEM model - a general view from the side of plane of symmetry (PS), the model with assigned attributes and FE grid

Below, an enlargement of the model of the cargo hold part in the zone of planned hit against the rock, is presented in Fig. 5 - showing its view from the side of PS, and in. Fig. 6. - its view from the side of outer plating.

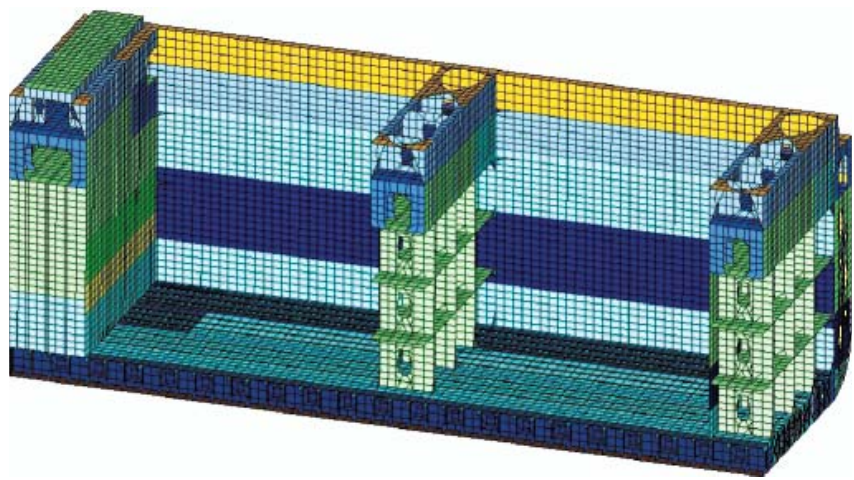

Fig. 5. FEM model - the enlargement of its hold part in the zone of the planned collision, seen from the side of PS 


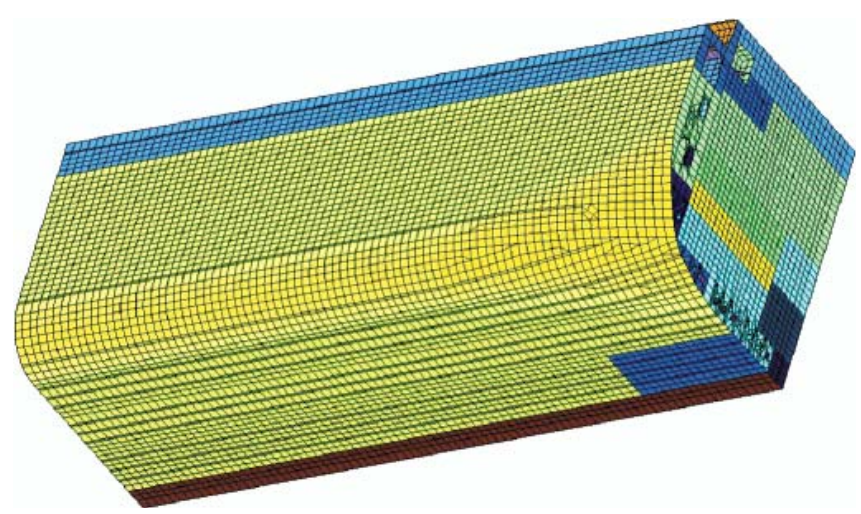

Fig. 6. FEM model - the enlargement of its hold part in the zone of the planned collision, seen from the side of outer plating

In the modeling process two kinds of material was used:

* for hull structures - steel of bilinear plasticity characteristics with determined damage limits, Tab.1.

* for the rock - a rigid and undeformable material.

Tab. 1. Parameters of the selected steel used in calculations of the entire model of the cargo hold part of the containership

\begin{tabular}{|c|c|c|c|}
\hline No. & Description & Unit & Value \\
\hline 1 & Young's modulus & $\mathrm{GPa}$ & 200 \\
\hline 2 & Poisson's ratio & - & 0.3 \\
\hline 3 & Density & $\mathrm{kg} / \mathrm{m}^{3}$ & 7865 \\
\hline 4 & Plasticity limit & $\mathrm{MPa}$ & 310 \\
\hline 5 & Strain hardening modulus & $\mathrm{MPa}$ & 768 \\
\hline 6 & Failure strain (deformation) & - & 0.75 \\
\hline
\end{tabular}

Relation between the rock and the ship's plating was assumed to be "the erosion contact", which means that to break continuity of the FE grid of the plating is possible.

The strain value equal to 0,75 was assumed to be the failure criterion.

\section{SIMULATION OF COLLISION}

The collision simulation was performed under assumption of a reverse process, i.e. such that the motionless ship hull was struck by the rock in horizontal motion with $20 \mathrm{~mm} / \mathrm{s}$ speed, Fig. 7.

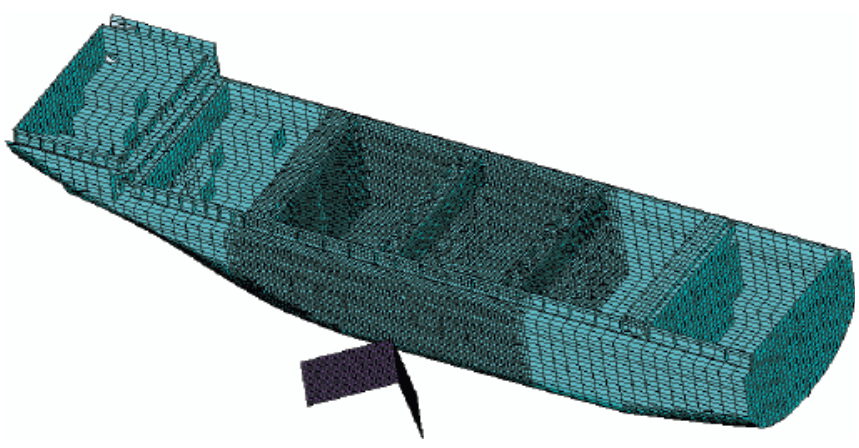

Fig. 7. A view of the cargo part of the containership together with the colliding object
During numerical calculations of ship-to-rock collision it is necessary to take into account the phenomenon of contact between different elements of the model. In the case in question it is difficult to predict which fragments will come into contact. The typical standard approach consisting in the use of a monitoring algorithm automatically determining which of the model elements take part in the contact, was assumed. The procedure for excluding the damaged elements made it possible to simulate the initial phase of the penetration of the ship plating structure by the rock and this way to cover the crucial phase of the collision.

Along with progressing penetration of the "rock" far into the plating structure its deformation occurs until the failure strain value is exceeded, that results in exclusion of the element. Below - in the successive figures -is presented the hull structure deformation process and associated rise of stresses up to occurrence of a hole in the side plating.

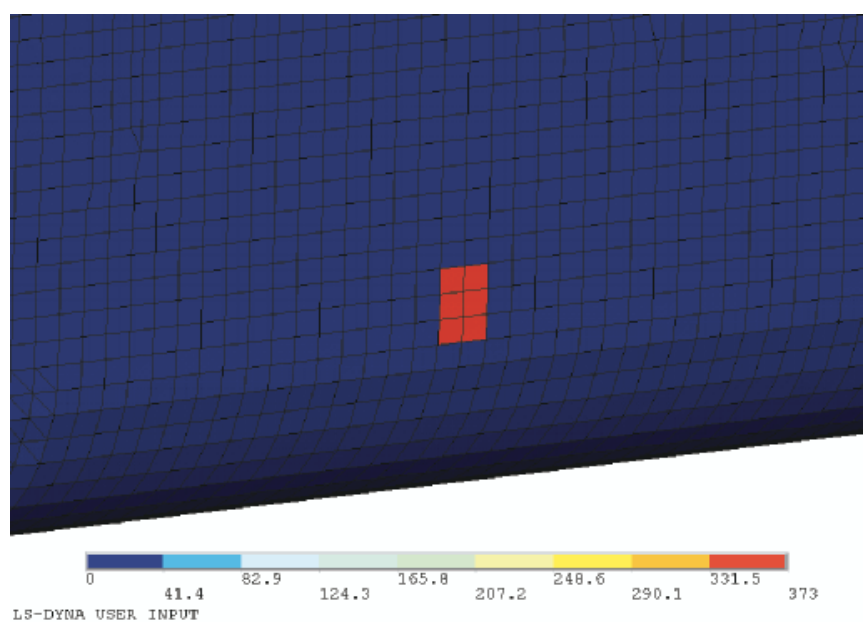

Fig. 8. Reduced stresses in side plating just before its rupture

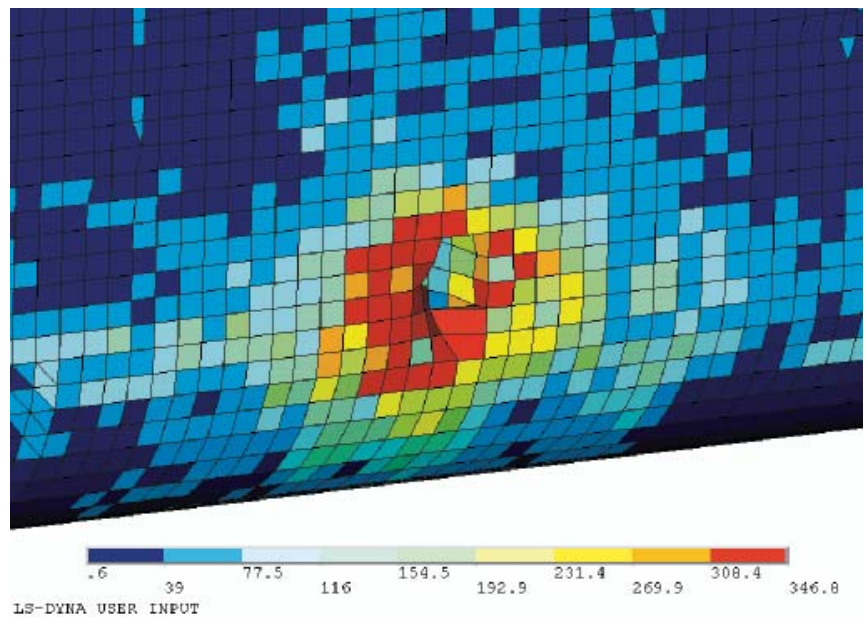

Fig. 9. Reduced stresses at the instant of 51 s passing from the beginning of collision - the moment of rupture of the outer plating

An analysis of force distribution in elements of the colliding model made it possible to determine changes in reaction of ship-rock interaction in function of time. In the diagram of the changes (Fig.10) it can be observed that during the penetration process two points of maximum occurred. The first - after first $10 \mathrm{~s}$ of the collision, that corresponds with $200 \mathrm{~mm}$ depth of the penetration, the other - after $22 \mathrm{~s}$ of the collision, that corresponds with $440 \mathrm{~mm}$ depth of the penetration. 


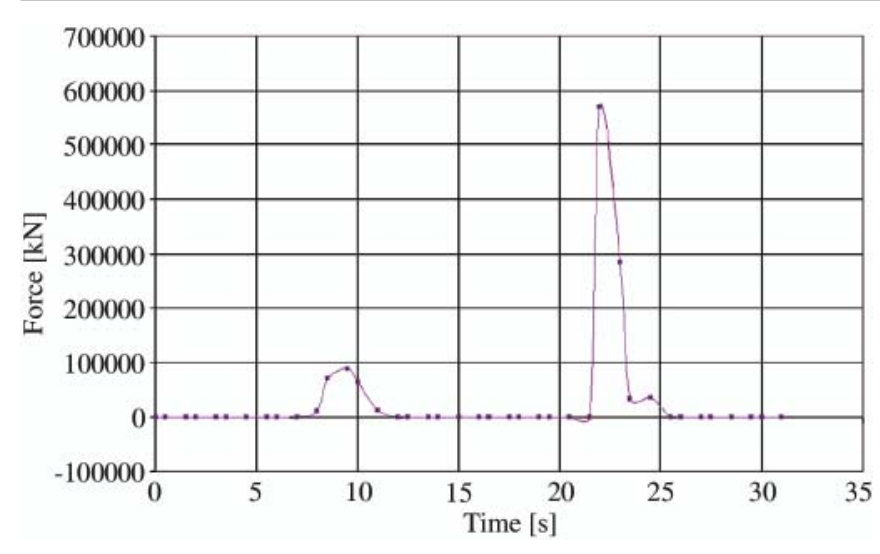

Fig. 10. The force-time diagram of interaction between the side plating structure and the ,rock”

\section{SUMMARY}

The performed simulation of the collision between the ship hull structure and rock is a slowly converging and timeconsuming process because of introduction of necessary and deliberate simplifications. The obtained results illustrate structural damage resulting from penetration of the plating by the rock.

The figures presenting the results show a stepped stress propagation and stepped damaging process of the side structure.

Behaviour of the kind is influenced by the bilinear material characteristics as well as FE grid density. A greater grid density could mitigate the steps, however the character of the process will remain the same.

The force-time diagram of interaction between the side structure and rock shows that the modeling metod applied to the simulation yields a character of local peaks up to the instant when the exclusion conditions of elements (failure strain $>0,75$ ) is reached.

More realistic values could be obtained if failed elements were left during simulation.

Application of the excluding procedure of the failed elements made it possible to simulate the initial phase of penetration of the plating structure by the rock, and this way to capture the crucial moment of the collision.

\section{BIBLIOGRAPHY}

1. ISSC : Report by Specialist Panel V.4 - Structural Design Against Collision and Grounding, Proceedings of the 13th International Ship and Offshore Structures Congress 1997, Trondheim, Norway, 1997

2. Ship Structure Committee : Modeling Structural Damage in Ship Collisions, SSC - 1400 Draft Report, 2002

3. Naar, H., Kujala, P., Simonsen, B.C. and Ludolphy, H. : Comparison of the crashworthiness of various bottom and side structures. Journal of Marine Structures, 15, 2002

4. Kujala, P., Romanoff, J., Tabri, K. and Ehlers, S. : All steel sandwich panels - design challenges for practical applications on ships. International Symposium on Practical Design of Ships and Floating Structures (PRADS), 2, Lubeck- Travemunde, 1217 September 2004.

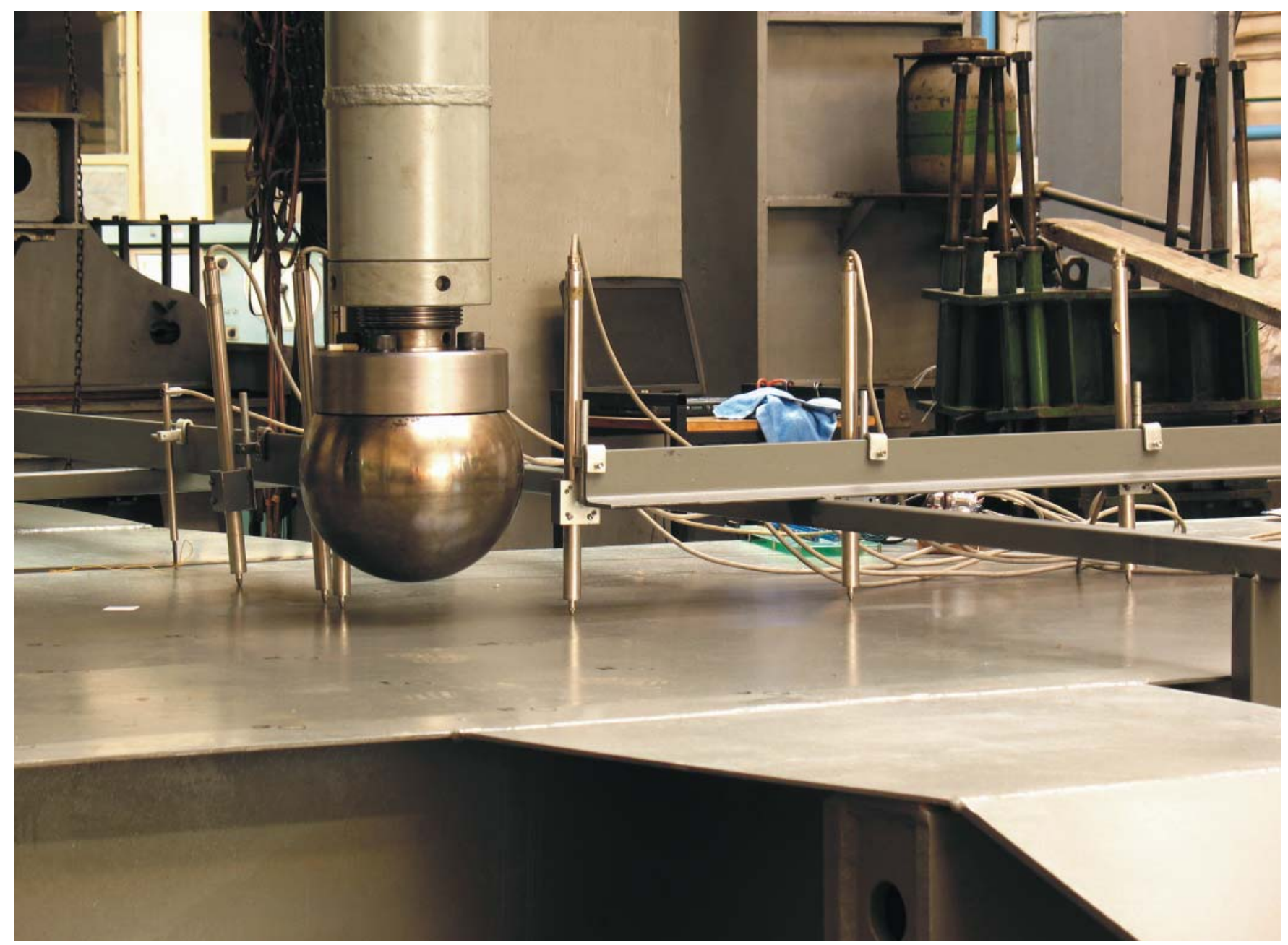

